Boletim Científico do Instituto Agronômico do Estado de São Paulo

\title{
ASPECTOS DA BANANICULTURA NO LITORAL NORTE PAULISTA ESTUDADOS ATRAVÉS DE FOTOGRAFIAS AEREAS ( ${ }^{1}$ )
}

ARnaldo Guido DE Souza Coelio e RaUl Audr, engenheiros-agrônomos, Serviço de Fotointerpretaçāo, Instituto Agronômico

\section{SINOPSE}

São relatados estudos efetuados nos municípios de São Sebastião, Caraguatatuba e Ubatuba, no litoral Norte do Estado de São Paulo, relativos à distribuição da cultura da bananeira. Os trabalhos foram executados com apoio em fotografias aéreas verticais, tiradas em 1962, na escala aproximada de $1: 25.000$.

Estimaram-se os totais de 2.606 ha, ocupados por 2.377 .500 pés de bananeira, localizados, quase totalmente, em solos das partes baixas da região. Cêrca de $60 \%$ da área plantada e $70 \%$ do total de pés estão localizados no municipio de Caraguatatuba.

Correlações de clima, solo e outras de interêsse para a cultura foram efetuadas.

\section{1 - INTRODUÇÃO}

O cultivo da bananeira, no Estado de São Paulo, é praticado no planalto e no litoral, suprindo, o primeiro, o mercado interno, enquanto o segundo caracteriza-se como zona produtora para exportação.

0 trabalho visa oferecer subsíduos para melhor conhecimento da situação geral desta cultura, a mais importante atividade agrícola no litoral Norte do Estado de São Paulo, nos municípios de São Sebastião, Caraguatatuba e Ubatuba, parte litorânea entre o município de Santos e o Estado do Rio de Janeiro, a Serra do Mar e o Oceano Atlântico.

Com base em fotografias aéreas, foi possível localizar as áreas cultivadas, determinar sua distribuição geográfica, o número de pés e a área ocupada, bem como a posição topográfica das culturas e os solos utilizados, além das correlações com elementos climáticos e outros dados de interêsse. 


\section{2 - MATERIAL E MÉTODO}

O trabalho foi desenvolvido com o emprêgo de fotografias aéreas verticais, de $23 \times 23 \mathrm{~cm}$, em escala aproximada de 1:25.000, tomadas entre junho e agôsto de 1962, com câmaras Fairchild 134 e Galileo Santoni, modêlo VI, de distâncias focais calibradas de 153,60 e $153,12 \mathrm{~mm}$, respectivamente, e mosaicos, não controlados, de $60 \times 60 \mathrm{~cm}$ de mesma escala que as fotografias.

No material fotográfico foram delimitados os municípios, com base em descrição oficial do Instituto Geográfico e Geológico, segundo a Lei 8092 de 28 de fevereiro de 1964. Em seguida fêz-se o reconhecimento, a localização, delimitação e avaliação (número de pés e área, em morros ou baixadas) das glebas cultivadas, segundo detalhes descritos no trabalho referente ao litoral Sul (11), usando-se, também, plantas topográficas publicadas pelo Instituto Geográfico e Geológico $(5,7)$.

Das fotografias (áreas descontínuas), os dados foram transferidos para os mosaicos (áreas contínuas), para posterior confecção de matrizes, registro permanente dos trabalhos efetuados.

A espécie mais cultivada no litoral é a Musa Cavendishii, variedades ou clones NANICA, NANICÃO e CONGO (6). Além dos espaçamentos recomendados de $3 \times 3 \mathrm{~m}$, nos morros, e de $4 \times 4 \mathrm{~m}$, nas baixadas (1), foi constatado o emprêgo de espaçamento de $2 \times 2 \times 5 \mathrm{~m}$, ou seja, duas linhas distanciadas de $2 \mathrm{~m}$, entre si, e separadas de $5 \mathrm{~m}$ das duas seguintes. Nas linhas, o espaçamento também era de $2 \mathrm{~m}$. O sistema de plantio adotado visa facilitar a prática de tratos culturais mecânicos.

\section{3 - REsultados E CONClusões}

Os municípios estudados ocupam área global de $1.641 \mathrm{~km}^{2}$ ou 164.100 ha, dos quais 2.606 estão ocupados por 2.377 .500 pés de bananeira.

No quadro 1 acham-se os registros dos cálculos efetuados, por município. Não se efetuaram avaliações estatísticas dos desvios, principalmente, pela impossibilidade de se proceder a contagens individuais nas fotografias e no campo.

A figura 1 evidencia que, no litoral Norte, a cultura da bananeira se acha concentrada no município de Caraguatatuba, o que vem perdurando desde o seu início, segundo se depreende de Schmidt (9). O escoamento da produção, normalmente, se dá através de transporte rodoviário.

Da estimativa de 2.606 ha cultivados, 157,6 ha são constituídos por glebas de solos bem drenados, com 174.800 pés de bananeira, enquanto 2.448 ha são de solos Aluviais ou Hidromórficos, com 2.203.000 pés de bananeira. 


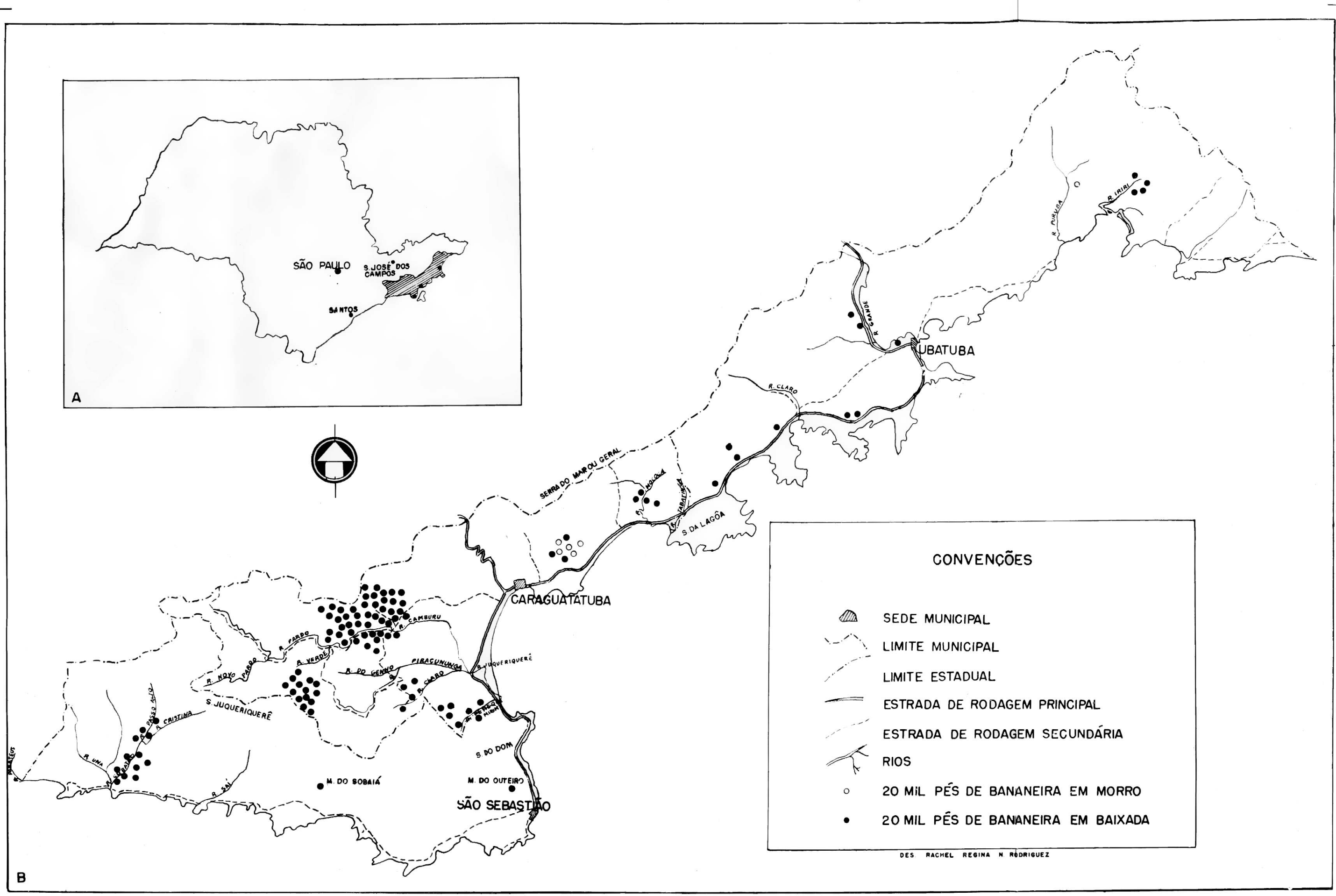

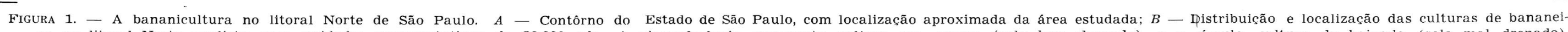

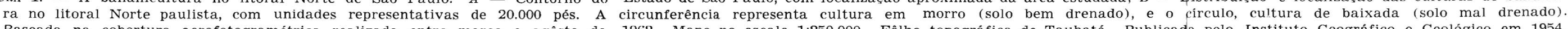

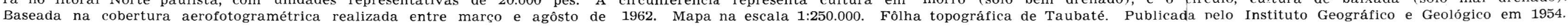


QUAdRo 1. - Levantamento da cultura da bananeira por municipio e sua distribuição por solos bem e mal drenados

\begin{tabular}{|c|c|c|c|c|c|c|c|c|}
\hline \multirow{3}{*}{ Município } & \multirow{3}{*}{ 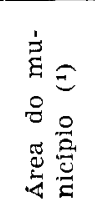 } & \multirow{3}{*}{ 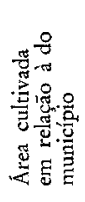 } & \multicolumn{2}{|c|}{ Estimativas totais } & \multicolumn{4}{|c|}{ Solos } \\
\hline & & & \multirow{2}{*}{$\begin{array}{l}\text { Em } \\
\text { área }\end{array}$} & \multirow{2}{*}{$\begin{array}{l}\text { Em n.? } \\
\text { de pés }\end{array}$} & \multicolumn{2}{|c|}{ Morro } & \multicolumn{2}{|c|}{ Baixada } \\
\hline & & & & & Area & Pés & Área & Pés \\
\hline São Sebastião & $\begin{array}{c}h \alpha \\
47.900\end{array}$ & $\begin{array}{c}\% \\
1,35\end{array}$ & $\begin{array}{l}h \alpha \\
647\end{array}$ & 412.400 & $\begin{array}{c}h a \\
16.0\end{array}$ & 17.800 & $\begin{array}{c}h a \\
631,0\end{array}$ & 395.000 \\
\hline Caraguatatuba & 48.000 & 3,23 & 1.553 & 1.690 .900 & 99,0 & 110.000 & $1.454,0$ & 1.581 .000 \\
\hline Ubatuba ... & 68.200 & 0,59 & 406 & 274.200 & 42,6 & 47.000 & 363,0 & 227.000 \\
\hline Totais $\ldots \ldots$ & 164.100 & 5,17 & 2.606 & 2.377 .500 & 157,6 & 174.800 & $2.448,0$ & 2.203 .000 \\
\hline
\end{tabular}

(1) Dados do Instituto Geográfico e Geológico, São Paulo.

Observou-se que o fungo causador do mal de Sigatoka (8) é de ocorrência geral, sendo o seu contrôle feito com óleo mineral. Convém notar que, em vista da localização e das características das culturas, o emprêgo de avião com nebulizadores talvez só se justifique no município de Caraguatatuba.

Destacaram-se, no relêvo acidentado, dois anfiteatros de maior extensão nas baixadas de Caraguatatuba e Ubatuba. $O$ exame estereoscópico dos pares fotográficos permitiu observar que, nestas áreas, a parte agricultável é maior, restringindo-se, nas demais, ao espaço entre os morros costeiros.

Os resultados mostraram haver áreas que possibilitam a expansão das culturas, considerando-se haver as condições requeridas pela musácea - baixa altitude, clima quente, úmido, e solos com propriedades físicas e químicas adequadas.

Nas áreas onde as culturas têm maior expressão, os bananais são adubados, do que decorre manter-se a fertilidade dos solos em níveis razoáveis, e principalmente, aumentando-se a produtividade.

Segundo a Carta de Solos do Estado de São Paulo, da Comissão Nacional de Solos, do Ministério da Agricultura (3, 4), as culturas de bananeira no litoral, município de São Sebastião, localizam-se em solos "Campos do Jordão" e Litosol, fase substrato granito-gnaisse, e em solos Hidromórficos.

A bananeira, planta tropical, encontra condições climáticas favoráveis no litoral Norte. Segundo a carta climática da Secção de Climatologia Agrícola (2), na borda do litoral aparece o tipo climático $A f$, conforme Köppen, clima tropical úmido, sem estação 
sêca, com temperatura média do mês mais quente superior a $18^{\circ} \mathrm{C}$ e chuva total do mês mais sêco superior a $60 \mathrm{~mm}$. Vai da baixada do litoral até o início da serra do Mar, onde passa para o clima mesotérmico, devido à amenização da temperatura, em decorrência da altitude. Segundo a carta de isoietas anuais de Shröder (10), a precipitação pluviométrica dêste tipo climático vai de $1.700 \mathrm{~mm}$ até ultrapassar $3.000 \mathrm{~mm}$.

A temperatura do mês mais quente oscila entre $24^{\circ} \mathrm{C}$ e $25^{\circ} \mathrm{C}$, nos meses de janeiro e fevereiro, que são os de maior precipitação. Chega a atingir a baixada litorânea, parte interiorizada e o sopé da serra do Mar, o tipo climático Cfa (2), clima mesotérmico úmido, sem estiagem, com temperatura média do mês mais quente superior a $22^{\circ} \mathrm{C}$, apresentando, no mês mais sêco, precipitação pluviométrica superior a $30 \mathrm{~mm}$.

\section{1 - MUNICIPIO DE SÃO SEBASTIÃO}

Neste município as plantações estão localizadas, em sua quase totalidade, nas aluviões próximas ao rio Una, ribeirões do Cubatão, Passo Alto e da Cristina, e também, nas proximidades dos morros do Sobaia e do Outeiro.

Ao longo do trecho São Sebastião a Bertioga, constatam-se culturas de grotas e glebas não definíveis nas fotografias.

Outra observação é que, na região mais intensamente plantada, parece haver ocorrido regressão da cultura, de 1962 para 1963, em algumas áreas.

\section{2 - MUNICÍPIO DE CARAGUATATUBA}

Neste município, observa-se predominância quase absoluta de cultivo em solos de baixada, praticado em 93,6\% do total.

Nesta região encontram-se $60 \%$ da área total cultivada no litoral Norte e $70 \%$ do número de pés. As culturas estão localizadas entre a serra do Juqueriquerê e o rio Verde, rios Claro, Camburu e serra do Mar; aluviões dos rios Perequê-Mirim e Jaraguá; rio Ipiranga e ribeirão Mococa.

A maior área de cultivo pertence à fazenda São Sebastião (fazenda dos Inglêses), com 837,0 ha e $\mathbf{1 . 1 9 5 . 0 0 0}$ pés, 50\% do total estimado no litoral Norte, o que é explicado pelo espaçamento empregado, de $2 \times 2 \times 5 \mathrm{~m}$, que determina 1.428 pés por ha, enquanto nos espaçamentos de $4 \times 4 \mathrm{~m}$ e $3 \times 3 \mathrm{~m}$ tem-se, respectivamente, 625 e 1.111 pés por hectare. Nessa propriedade, a área cultivada é servida por linhas férreas, o cultivo é racional, os tratos culturais são mecânicos nos espaços de $5 \mathrm{~m}$, praticando-se roçada nos de $2 \mathrm{~m}$, existindo planos para futura expansão da cultura. 
Esta área faz parte da bacia formada pelos rios Pardo, Verde, Camburu, Claro e Juqueriquerê, considerada por Schmidt (9) como a mais importante zona de cultivo do litoral paulista, com 12.000 ha cultiváveis, comportando um total de 10 milhões de bananeiras.

Quanto aos solos cultivados e ao clima, valem as observações feitas para o município de São Sebastião.

\section{4 - MUNICÍPIO DE UBATUBA}

Este município ocupa a maior parte do litoral Norte, ou seja, 68.200 ha, dos quais 406 cultivados com bananais, representando $0,59 \%$ da área total.

Nos solos das partes baixas são cultivados 363,0 ha, e nos solos das partes altas, 42,6 ha, com 227.000 e 47.000 pés de bananeira, respectivamente.

As glebas com bananais localizam-se nas proximidades do rio Maranduba, da estrada Caraguatatuba-Ubatuba, do ribeirão Grande e rios Puruba e Iriri.

Os rios Acaraú e Puruba pràticamente constituem o limite das observações de campo, pois, a partir dessa árrea, em demanda do limite com o Estado do Rio de Janeiro, não existem estradas.

De acôrdo com a Carta de Solos do Estado de São Paulo $(\mathbf{3}, \mathbf{4})$, os solos dêste município, cultivados com bananeiras, são constituídos de Latosol Vermelho Amarelo - fase rasa; solos "Campos do Jordão" e solos Hidromórficos.

\section{SOME CHARACTERISTICS OF BANANA PLANTATIONS ON THE NORTHERN COAST OF SÃO PAULO STUDIED THROUGH AERIAL PHOTOGRAPHS}

\section{SUMMARY}

There are reported studies carried out in the counties of São Sebastião, Caraguatatuba and Ubatuba, on the north coast of the State of São Paulo, relative to distribution of banana cultures. Work was done with the help of vertical aerial photographs taken in 1962 on the approximate scale of $1: 25,000$.

A total of 2,606 ha was estimated holding 2,377,500 banana plants, located almost in their totality on soils of the lowlands of the region. About $60 \%$ of the planted area and $70 \%$ of the total of plants are located in the Caraguatatuba county.

Correlations of climate, soil and others of interest for this crop have been worked out. 


\section{LITERATURA CITADA}

1. Camargo, A. Pais De. Instrucooes agrícolas para o Estado de São Paulo. Campinas, Instituto Agronômico, 1961. 34p. (Boletim Técnico n. ${ }^{\circ}$ 45).

2. Climatologia Agrícola. Carta Climática do Estado de São Paulo. Campinas, Instituto Agronômico, 1962.

3. Comissão de Solos, Serv. Nac. Pesq. Agronômicas - Carta de solos do Estado de São Paulo. Rio de Janeiro, I.B.G.E., 1960.

4. Levantamento de reconhecimento dos solos do Estado de São Paulo. Rio de Janeiro, Serv. Nac. Pesq. Agronômicas, 1960. 634p. (Boletim n." 12)

5. Comissão Geográfica e Geológica. 1. ${ }^{a}$ Seção. Exploração do Litoral. Cidade de Santos à fronteira do Estado do Rio de Janeiro. São Paulo, Tipografia Brasil, 1915. 21p. ( 5 plantas topográficas).

6. Cortez, J. V. Contribuição para o estudo da bananeira no litoral do Estado de São Paulo. Observações sôbre ciclos. Piracicaba, Esc. Sup. Agricultura "Luiz de Queiroz", 1961. 46p. (Tese de doutoramento mimeografada).

7. Instituto Geográfico e Geológico. Fôlha topográfica de Taubaté. São Paulo, Gráficas Ipiranga, 1954.

8. Lopes, F. C. Nelson. A "cercosporiose" da bananeira. Divisão de Defesa Sanitária Vegetal. Rio de Janeiro, Ministério da Agricultura, 1960. 34p.

9. Schmid, C. B. A cultura prática da bananeira nanica no litoral Norte Paulista. Secretaria da Agricultura, Indústria e Comércio do Estado de São Paulo, Diretoria de Publicidade Agrícola, 1934. 179p.

10. ScHRöDER, R. Distribuição e curso anual das precipitações no Estado de São Paulo. Bragantia 15:[193]-249. 1956.

11. Verdade, F. C., Borgonovi, M., Chiarini, J. V., Audi, R. \& Coelho, A. G. DE SouzA. Estudo, por fotointerpretação, da cultura da bananeira no litoral Sul. Campinas, Instituto Agronômico, 1964. (Boletim n. ${ }^{\circ}$ 136) 